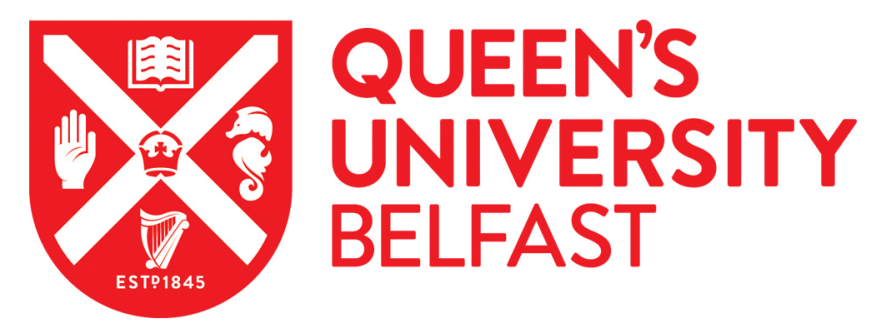

\title{
Technology and behaviour analysis in higher education
}

Keenan, M., Presti, G., \& Dillenburger, K. (2019). Technology and behaviour analysis in higher education. European Journal of Behaviour Analysis. https://doi.org/10.1080/15021149.2019.1651569

\author{
Published in: \\ European Journal of Behaviour Analysis
}

\section{Document Version:}

Peer reviewed version

Queen's University Belfast - Research Portal:

Link to publication record in Queen's University Belfast Research Portal

\section{Publisher rights}

(C) 2019 Norwegian Association for Behavior Analysis.

This work is made available online in accordance with the publisher's policies. Please refer to any applicable terms of use of the publisher.

\section{General rights}

Copyright for the publications made accessible via the Queen's University Belfast Research Portal is retained by the author(s) and / or other copyright owners and it is a condition of accessing these publications that users recognise and abide by the legal requirements associated with these rights.

Take down policy

The Research Portal is Queen's institutional repository that provides access to Queen's research output. Every effort has been made to ensure that content in the Research Portal does not infringe any person's rights, or applicable UK laws. If you discover content in the Research Portal that you believe breaches copyright or violates any law, please contact openaccess@qub.ac.uk. 


\title{
Technology and Behaviour Analysis in Higher Education
}

\author{
Mickey Keenan ${ }^{1}$, Giovambattista Presti ${ }^{2}$, \& Karola Dillenburger ${ }^{3}$ \\ accepted in European Journal of Behaviour Analysis (30 July 2019)
}

1. School of Psychology, Ulster University, N. Ireland

2. Facoltà di Scienze dell'Uomo e della Società, Kore University sEnna, Italy

3. Centre for Behaviour Analysis, Queen's University Belfast, N. Ireland

\begin{abstract}
A key goal of higher education is to provide training that harnesses cutting-edge developments in both the theory and applications of a particular discipline. Currently in Europe, the up-take of the discipline of behaviour analysis is thwarted by a range of factors, the primary one being a hostile environment fuelled by misunderstandings of the science and its applications. In this paper, we offer suggestions for how to use behavioural as well as digital technology creatively to address this problem. We start with an overview of baseline conditions in which misinformation is rife, particularly in the field of autism interventions. We argue that, in advocacy for better services, there is a need for a more systematic use of behavioural technology. We call for the creation of a database of teaching gambits that provide illustrations of how to teach compleX conceptual issues as well as guidance on running practical classes in the experimental analysis of behaviour. Furthermore, we eXamine the design of the discriminative stimuli used when explaining the natural science of behaviour, including the persistent reliance on the written word alone when discussing something dynamic like behaviour. We propose that behaviour analysts should embrace digital technology to develop these stimuli and we give some examples of how to harness this technology to develop an ecosystem that supports the coordination of behavioural services and the enhancement of treatment integrity. We consider how cloud-based archives can be used to keep track of behavioural progress and provide a learning management system that might potentially work with social robots, iPads, and interactive walls. Finally, we summarize how these issues are directly related to making the science of behaviour analysis accessible and fit for purpose for students and service users in the $21^{\text {st }}$ century.
\end{abstract}

Key words: $A B A$, autism, misrepresentation, Higher Education, teaching gambits, technology 
For behaviour analysts, the general idea of using behaviour analysis for developing students' skills in Higher Education (HE) needs no introduction. Accordingly, we will focus our discussion in this paper on the following three issues related to the use of behavioural and digital technology in the dissemination and promotion of behaviour analysis:

1. Using behavioural technology strategically in advocacy for service provision. By-and-large applied behaviour analytic interventions continue to be underrepresented in Europe. We discuss issues that impede training and employment of behaviour analysts and call for a Europe-wide appreciation of the need to use behavioural technology in advocacy.

2. Training the professionals for the job and using digital technology in HE teaching. Apart from the general use and frequent misuse of PowerPoint (Taylor, 2007) and the occasional video downloaded from YouTube, most behaviour analysts use very little digital technology in their teaching. Our aim here is to highlight some concerns about the limited way in which advantage is taken of currently available digital technology when teaching behaviour analysis.

3. Supporting service users on the job with assistive and behavioural technology. This is a fast-developing field and there is much to learn. It is important that behaviour analysts stay at the forefront of these developments (Twyman, 2016). We outline some recent eXamples to ensure that students are fluent in the use of behavioural and digital technology.

Of course, these issues are interrelated and together they affect the degree to which the field of Applied Behaviour Analysis (ABA) is promoted in Europe. We begin this discussion by eXamining the baseline conditions in Europe that make their discussion relevant. Given the focus of this paper, we will not be discussing in full the use of telehealth for the delivery of behaviour analytic services. For a systematic review of issues related to telehealth see Ferguson et al. (2018).

The dissemination of behaviour analysis across the USA has been greatly aided by the relatively recent developments in legislation that mandate funding of interventions based on ABA for individuals with autism (Autism Speaks, 2014). The proliferation in legislation to ensure access to $A B A$ services has not come without a fight, though, as described in some detail by Unumb (2013). Through concerted advocacy by parents and professionals, behaviour analysts are now recognised in the USA as key professional in autism services, in many cases behaviour analysts are State licensed professionals (BACB, 2018). This is not the case in Europe. Communicating with parents about $A B A$ interventions is already challenging in a conteXt where the available teaching material is readily available in English (Helton \& Alber-Morgan, 2018). It is easy to appreciate how much more difficult it is to do the same job in a conteXt with many different languages, cultural practices, diverse regulatory environments, idiosyncratic national educational structures, and limited teaching materials.

\section{Using behavioural technology strategically in advocacy for service provision}

While there are agreed training and practice standards with automatic recognition across Europe for some professions (e.g., nurses, midwifes, doctors, general practitioners and veterinary surgeons) (European Parliament, 2005), most professions are regulated differently in each European country. 
In each EU country, workers are required to obtain special qualifications or specific job titles to perform regulated professions. Different requirements across the EU may make it difficult for qualified professionals to apply for jobs in other EU countries. It may also be difficult to get information on what conditions these professionals have to comply with to be able to work in another country. (European Commission, 2018)

To help navigate this compleXity, the European Commission provides a webpage with links to national contact points that provide information on the national rules and advice on workers' freedom of movement rights (European Commission, 2018). By contrast, ABA has encountered numerous obstacles in Europe that impede the acceptance of both the science and its professional standards (BACB, 2018). So far, none of the European countries have officially recognised the profession of behaviour analysis, with the exception of the Czech Republic (Gandalovicova, 2016). Here, a law was adopted in 2017 to protect professional titles and standards, largely based on those set by the Behavior Analyst Certfication Board (BACB, 2018).

The lack of professional recognition across Europe means that the practice of $A B A$, particularly in the field of autism, has fallen prey to misunderstandings and, at times, misapplication (Dillenburger, McKerr, \& Jordan, 2014a; Keenan et al., 2014; PEAT, 2002). As a consequence, nearly all European countries have experienced eXplicit anti-ABA propaganda (e.g., Keenan et al., 2015; Keenan \& Dillenburger, 2018; Kelly, Martin, Dillenburger, Kelly, \& Miller, 2018) initiated either by academics not trained in the science of behaviour analysis (Baron-Cohen, 2014; Jordan, 2001; The Skeptical Advisor, 2014), or by self-appointed 'autistic advocates' (Milton, 2012; Kupferstein, 2018). The resulting misinformation about ABA politicises the environment in which the science is taught.

Lupia (2013) addressed the problems of communicating science in politicised environments. Although not a behavioural paper, his discussion is relevant for readers of this journal insofar as behaviour analysts are acutely aware of the importance of environmental contingencies in generating and maintaining socially relevant behaviour. As (Skinner, 1980) put it:

One can picture a good life by analysing one's feelings, but one can only achieve it by arranging environmental contingencies. (p. 127)

To set the scene for Lupia's statement, it is useful to look at Todd and Morris (1983) who described a major source of the problems. In their review of misinformation about behaviourism in psychology teXtbooks, they concluded that there was indeed evidence of major concern:

To the extent that public policy is shaped by individuals whose exposure to behaviorism is through teXtbooks such as those reviewed in this study, and through educators who assign those teXtbooks, then these policies and decisions are not likely to reflect the important conceptual and applied contributions that a natural science of behavior can offer. (p. 158)

Correcting misinformation in teXtbooks, they suggested, involves a significant and sustained effort on the part of behaviour analysts who need to contact publishers and/or authors and may run into problems with those authors, who may have staked their 
reputation and/or career on misinformation about $A B A$.

Todd (1987) advises:

If behaviorists can correct the pervasive misconceptions regarding their views, then "the ultimate demise of behaviorism" (Gould, 1982, p. 9) may be prevented. If not, then, behaviorism's demise will not be the result of its "inability to come to grips" with innate behavior, but due to the inability of others to come to grips with the subtlety and compleXity of behaviorism. (p. 118)

At first sight, this is a seemingly sensible conclusion. However, it is incomplete. From a pedagogical perspective, it is the teachers of behaviour analysis who are responsible for ensuring that their audience is able to appreciate the subtlety and compleXity of behaviourism. Since the quality of teaching in HE eventually impacts on policy makers, students need to be sensitised to translational issues. This is because the "uptake of new and evidence-supported procedures is not automatic and cannot be assumed" (ViruésOrtega \& Yu, 2018, p. 9).

In many respects, this is the point made by Lupia (2013). Although he was not concerned with behaviour analysis per se, he was talking generally about science education. In particular, he was focussed on the frustration experienced by scientists when their findings are badly received, especially in 'settings where decisions on divisive public issues must be made' (p. 14048). The main point of his discussion was the need for scientists to adjust the way they communicate the results of their research.

Describing these discoveries and relationships often requires new language or using eXisting language in unusual ways. Many nonscientists, however, find our leXicon difficult to access: they see many scientific presentations as needlessly abstract and disconnected from their lives. Audiences who see scientific presentations in these ways have less motivation to pay attention to them. If such motivations are sufficiently low, seeds for communicative failure are sown. (p. 14048)

This is not an issue to which behaviour analysts have been blind (Keenan, 2016; LedouX, 1987; Skinner, 1981), but the energy needed to correct misinformation continuously can create the feeling that one is dealing with a bottomless pit (Spinzy \& Cohen-Rappaport, 2016).

This is not to dismiss the value of advocacy. On the contrary, advocacy and accurate dissemination is an important issue in science (AAAS, 2018; Unumb, 2013), especially when misrepresentation blocks the potential for significant positive impact on the lives of others. For it to be effective, though, advocacy has to be strategic and it needs to utilise behavioural technology comprehensively (Dillenburger, McKerr, \& Jordan, 2014b; Keenan \& Dillenburger, 2018; Kelly et al., 2018; Virués-Ortega \& Yu, 2018). Skinner (1953) recognised the compleXities involved in applying behavioural technology for changing cultural practices:

Practical situations are almost always more compleX than those of the laboratory since they contain many more variables and often many unknowns. This is the special problem of technology as against pure science. In the field of human behavior, particularly in the design of culture, we must recognize a kind of compleXity in the face of which the rigor of a laboratory science cannot be maintained. But this does not 
mean that science cannot contribute to the solution of crucial problems. It is in the spirit of science to insist upon careful observation, the collection of adequate information, and the formulation of conclusions which contain a minimum of wishful thinking. (pp. 434-435)

In relation to advocacy, Skinner's comments refer to a technology of behaviour that has to be strategic and incorporate data-based decision making. Unfortunately, the value of developing such a coherent strategic approach to advocacy is generally not appreciated by behaviour analysts in Europe. In fact, there is an urgent need to develop a central forum within the European Association of Behaviour Analysis (EABA) comprising parents and ABA professionals to facilitate the sharing of strategies that have produced the successes and failures in each country with respect to the promotion of behaviour analysis. Such a forum should seek to ensure that future strategies are planned strategically and that they are based on an assessment of antecedents, behaviour, and consequences.

In Ireland, for eXample, parents of children with autism have complained that behaviour analysts seem to leave it up to parents to fight for evidence-based practices (McCormack, 2012; 2015). Instead of parents and professionals working together as they have done in the USA (Unumb, 2013), parents of children with autism feel that often they are asked to provide their children for research purposes so that professionals can enhance their research profiles at the expense of ensuring that their science is supported by government bodies (McCormack, 2012; 2015). Clearly, this is a contentious point, but it draws attention to the kinds of conflict that can arise when there is no joint strategic plan for changing social contingencies. The result is that $A B A$ is either viewed as the problem (Kupferstein, 2018), as not even worth mentioning (Howlin, 2013), or as not providing enough evidence to be included in major reviews (NICE, 2016).

A non-strategic approach to advocacy leaves a vacuum, often with the result that 'fake news' about ABA dominates discussion at policy levels (Keenan \& Dillenburger, 2018). An eXample occurred at an event held in London, England, when the Westminster Commission on Autism (2018) launched their report into healthcare fraud in relation to autism. The report aimed to 'make the world a more autism-friendly place and free from charlatans who peddle harmful products, therapies and treatments for autism with no evidence-base' (Westminster Commission on Autism, 2018, p. 1). The focus of the report was on protection from dangerous and harmful 'cures' (such as bleach, eXorcism, and chelation, p. 6). At the event, there was a laminated sheet designed for people to sign their name and take a photo for social media, to show their support. The sign contained (1) the well-known location and name of the event ('Westminster Commission on Autism') and (2) all the sponsors' logos. The sheet had a space for people to sign their names in support of the report being launched. Many politicians (MPs) took the opportunity to associate with this worthy cause.

Neither the report, nor the sponsors of the event, mentioned ABA-based interventions. Yet, the occasion was seized upon by a small number of self-appointed autistic advocates who wrote "ABA is abuse" on the laminate and distributed their photograph over social media, thus giving the erroneous impression that the sponsors of the event agreed with their statement. Leaving aside the effects of the social transmission of misinformation, it is not clear what contributed to such a virulent backlash against ABA or why the whole science was targeted. Of course, there may be some malpractice, however, intriguingly, other disciplines, for eXample medicine, seem to remain relatively unscathed when malpractice is exposed. In fact, even mass murder does not seem to leave a mark on 
the reputation of medicine as a scientific discipline (Gunn, 2010). Similarly, the teaching profession is not condemned for historical practices that included corporal punishment (i.e., 'the intentional application of physical pain'; Greydanus et al., 2003, p. 385) by teachers; this was legal in Northern Ireland until 2003, yet teachers remain respected and highly regarded by the general population. It is remarkable that the whole discipline and profession of behaviour analysis is condemned, for some historical incidents of malpractice.

Finally, and although not confined to Europe, it is important to mention an additional ingredient in this toXic miX of obstacles that impede the uptake of $A B A$ in Europe. There is a serious problem created by people with commercial interests who promote their branded version of an ABA-based technology ahead of promoting the scientific discipline (cf., Freeman, 2003; Keenan, Dillenburger, Moderato, \& Röttgers, 2010). If professionals trained in the science of $A B A$ are truly interested in helping people, it seems reasonable to expect they would connect with local organisations to help develop strategic plans that take into account the local landscape of cultural practices, policies, and service provision, lest governments mistakenly are encouraged to invest in one of the branded products at the eXpense of investing in training in the science. This point is evident in the NICE (2015) guidelines on challenging behaviour in the UK that acknowledge $A B A$ as the basis of their preferred model of intervention (i.e., Positive Behaviour Support), yet $A B A$ is not included in their list of recommendations. Parents who advocate for ABA cannot understand why a specific ABA-based model is promoted but the science itself is not. In contrast, quite a different problem eXists in Italy. Italian guidelines on the treatment of autism spectrum disorders (Istituto Superiore di Sanità, 2015) specifically recommend ABA in early intervention and childhood, however, no specific professional profile in the science is required by the regulations of the National Health System, thus leaving the field wide open for those with very little training in the science.

Collectively, the confusion above is symptomatic of the problems created by what might be described as cultural chauvinism on the part of professionals whose actions lead policy makers to view the science of behaviour analysis as something that should only play second fiddle to a particular branded ABA-based model. Unfortunately, the muddied waters that have been created in turn have churned up a variety of issues across Europe as eXemplified by the following questions:

1) Should a government invest in the science of $A B A$, or in one specific $A B A$-based model?

2) Is it true that training in $A B A$ according to standards outlined by the $B A C B$ is not necessary when staff are trained in one model instead?

3) Does training to Masters level in ABA provide the same level of training as a course in one specific ABA-based model?

4) There have been no laws passed in the USA to guarantee parents have access to one specific ABA-based model. Instead, those laws reference the value of ABA. Why is it so different in the UK or in other European countries?

\section{Using digital technology in HE teaching}

It is intriguing that in a media-rich world most materials available for teaching behaviour analysis are primarily teXt based. Even online courses often involve students having to read lengthy PDF files or other teXts; for eXceptions see, Rethink (www.rethinkfirst.com) and SimpleSteps (www.simplestepautism.com). Keenan and 
colleagues (Keenan \& Dillenburger, 2014; Roll-Pettersson, Ala'i- Rosales, Keenan, \& Dillenburger, 2015) have outlined the limitations of the printing press when teaching both conceptual and applied issues in behaviour analysis. What follows are suggestions to stimulate appreciation of how the full remit of available digital technology (e.g., multimedia) can be used more creatively in teaching. Obviously, the detailed design of these kinds of alternative teaching methods requires skilled developers working in collaboration with behaviour analysts (Layng, 2014).

Death by power point. When Microsoft PowerPoint first became available to teachers, it ushered in a new way to present compleX information. However, this led to an overreliance on the software, so much so that the term 'Death by PowerPoint' (Taylor, 2007) entered the academic parlance. Classic mistakes include badly designed graphics, too much teXt on the slides and the teacher simply reading the content of the slides out loud. In addition, PowerPoint presentations are universally created according to a linear format because of the nature of the medium, where one slide follows the neXt. On the other hand, the material to be taught, behaviour and associated contingencies, are multi-faceted and often non-linear and therefore cannot be adequately presented by this software that forces a lockstep presentation of the material.

Though a skilled user could overcome the issue of linearity with internal hyperlinking and a little bit of effort in planning and eXecuting, it is not surprising that audiences are often left feeling that it would be better and quicker to read the material on a pamphlet instead of spending so much time listening to someone reading slides. More worryingly, when behaviour analysts present graphs of behavioural data on PowerPoint, those already antagonistic towards ABA may feel vindicated in their views by the way that the life of a sentient being is represented as a static dot on a graph. The point here concerns carelessness in the design of discriminative stimuli used when communicating scientific findings to a lay audience, especially when this occurs in a politicised environment.

The design problem is how to retain the scientific short-hand associated with using data points and at the same time provide the social discriminative stimuli associated with a person behaving. Figure 1 shows one simple way how this might be achieved using 'animated data points'. The image shows a data point that has been activated to reveal a video clip from which the data point was created. Until the necessary software is developed to simplify the creation of this kind of presentation, Figure 2 outlines how using PowerPoint makes this relatively easy:

(1) Duplicate the slide with the graph, once for each data point to be animated.

(2) Create hyperlinks to each of these duplicates so that when you arrive at a duplicate you will see a video clip associated with the appropriate data point. Working on the original slide (Slide 1), insert and adjust the size of circular shapes (let's call them proxy data points) so that each one covers the data point you want to animate.

(3) On Slide 1, insert a hyperlink from one proxy data point to one of the duplicate slides; Slide 2, for eXample.

(4) On Slide 2, insert a video clip that shows the behaviour for the data point. Make sure to resize the video so that it does not cover the rest of the data. Also, copy and paste the proXy data point so that it covers the data point on Slide 2. However, you need to remove the hyperlink and change its colour. Changing 
the colour is the discriminative cue for showing the data point has been activated, as shown by the video clip. Removing the hyperlink simply deactivates any further navigation from this data point.

(5) Repeat Steps 3 and 4 for each data point you wish to animate, only this time navigate to different duplicate slides for each data point. Doing this means that each proXy data point takes you to its own specific slide with its own specific video clip.

(6) Finally, you now need to replicate the process of creating proxy data points for each of the duplicate slides so that each proxy data point navigates to the corresponding slide containing its video clip. If you want to show a clip for each data point, then you need to create hyperlinks on all the data points on all of the slides.

During the presentation, the presenter simply clicks on the data points on the graph (which, in fact, are all proxy data points superimposed on the graph) and a video clip appears; the audience sees no change in the background graph, and they simply see the data coming alive in the video clip. The end result is something that does not affect the integrity of the scientific presentation but which augments it in a way that enhances opportunities for increasing social validity.

QR codes. Another relatively easy way to use digital technology in teaching is through the use of Quick Response (QR) codes (Keenan, 2016). These are bar codes that can be scanned by any smartphone (or tablet) using a free downloadable piece of software (i.e., a $Q R$ reader or Barcode reader). The $Q R$ code links to a specific webpage that is displayed when the QR code is scanned. This can be very useful when creating a hand-out for students or for a conference presentation. By offering a QR code, students simply scan the code with their phone to see, perhaps, a video clip showing the behaviour being discussed. In effect, this is one way to augment the printed word insofar as it makes the behavioural phenomenon come alive for an audience. In Figure 3, the QR code on the left links to a YouTube presentation showing how to create and use QR codes; the QR code on the right links to a demonstration of Discrete Trial Training (DTT) on YouTube.

Another suggestion for using QR codes is to include them in the BACB Task List (BACB, 2018). In effect, this would turn the task list into a database showcasing standardised procedures that could be used for teaching and learning. An open source or Creative Commons culture of sharing could be developed whereby individuals with the necessary skills would lead by eXample and stimulate others to contribute.

Animation. Animations that give the illusion of behaviour can be created by skilled animators who have undergone extensive training. However, the availability of some elegant software means that it is within reach of those less experienced to produce amazingly good-quality animated teaching materials. Figure 4 (left-hand panel) shows a tutorial introducing one eXample of this kind of software using 'Poser' (Lau, Chai, Xu, \& Shum, 2009). With some practice, animations can be used for recreating behaviour for training purposes that would otherwise raise ethical issues if they were recorded in real life. Figure 4 (Right-hand panel) illustrates this point with animations of a simple example of challenging behaviour. 
There are no limitations to what can achieved with animations of behaviour that are going to be discussed in class. Behaviour analysts working in HE could, for eXample, create an animation based on real baseline data and then extend that animation to show the results of an intervention designed to change these data. Alternatively, animations could be used to address conceptual issues, for eXample, Figure 5 (Left-hand panel) is a screenshot from a simple animation showing imitation.

Once the characters have been placed in a 3D environment to create the animation, they can be duplicated and placed in various spaces within the 3D environment to encourage discussion of the synchronisation between two behaviour streams across time (Figure 5, right-hand panel). In other words, the 3D environment of animation software permits key features of an animation to be extracted, thus providing more precise discriminative control over any conceptual arguments to be made about the behaviour in the animation. Once created, these animations and associated graphics can then be imported into the multimedia environment of a PowerPoint presentation for easy display in the classroom.

Discrete trials. It is important to be creative in designing the interface for managing the user's experience when navigating compleX issues. Figure 6 gives an eXample of how to present issues that arise when implementing a discrete trial for teaching a child with autism. For aesthetic reasons, the three-term contingency was designed to include the image of a child and for each of the elements (i.e., Antecedent, Behaviour, Consequence) there is a list of problems that might arise during the implementation of the learn unit. Thus, for eXample, under Antecedent, if a problem is encountered such as a child's hands not being 'quiet' before the start of the trial, then a video clip eXample of this behaviour could be called up via a hyperlink (created in the same way as described above in Figure 2) and appear in the space beneath the child in the image along with suggestions on how to manage this behaviour. Similarly, if during the trial, the child begins running around then a click on that term listed under Behaviour would show a clip illustrating how to manage this kind of behaviour. The same strategy for organizing problem solving clips is designed for issues that may arise under the heading 'Consequence'. In effect, this interface collapses a huge amount of information into one image and the resulting discriminative control makes it easier for students to categorise problems in line with the structure of the three-term contingency.

Such a tutorial is in stark contrast to a teXt-only tutorial or a single video tutorial on the three-term contingency that can be difficult to navigate when reviewing a number of different issues at the same time. Further examples of the use of animations to teach behaviour analysis can be found in SimpleSteps (2013), a multi-lingual online multimedia resource for parents of children with autism and professionals working in the field (STAMPPP, 2013).

Construction of a manual for teaching gambits. The idea that there is no need for private events in the explanation of behaviour (Baum, 2011) is perhaps one of the most difficult issues to convey effectively to students without leaving an audience with impression that people are to be viewed as black boXes, or zombies (as shown in Figure 7). Most of the writing on private events in behavioural literature merely repeats Skinner's insights from the late 1930s. When you consider that the topic is of central importance to a student's personal reflections on his/her own 'private world', there is a clear need to 
develop in-class eXercises to help explain how to address the relation between private and public behaviour. Carefully designed gambits should also accommodate those students with little or no training in the philosophy of science.

Keenan and Dillenburger (2000) and Keenan (2015) offer some suggestions for developing this kind of educational technology to address a range of different issues. For eXample, students are usually taught about how to analyse the 'private events of another person', but not 'their own private events'. There are few standardised procedures that help teachers guide students through such epistemological issues when they (i.e., the students) self-reflect. Lupia (2013) touched on the value of designing effective gambits:

If we take the time to make presentations that produce relevant and credible new memories for our audiences, we can help them to replace false beliefs with knowledge that scientists have evaluated and validated. Our claims can be memorable and persuasive while staying true to the science that we have discovered. (p. 14053)

The question for a novice teacher of behaviour analysis is where to find ideas and directions for running a practical class on topics ranging from the experimental analysis of behaviour to applied issues in behaviour analysis. Usually, scientists publish research with attention to detail on the procedures used so as to permit replication. Yet, when it comes to effective teaching, it is hard to find any guidance on effective procedures that teachers can replicate in class. Clearly, a behavioural science should make the creation of such a manual a priority given that in-class practicals form the basis of much scientific training generally. New as well as experienced teachers need support for running 'practicals' in class so the material covered becomes interesting for students when training relevant skills. With such a manual, teachers could dip into a wide range of suggestions that can be adapted to suit their particular conteXts. For eXample, such a manual could contain guidance on how to run an in-class practical on schedules of reinforcement, to name just one topic in the experimental analysis of behaviour that can be difficult to teach without lab facilities. Students may not be interested in animal research per se, but an understanding of the essential features of the analysis of contingencies of reinforcement is an important part of their training in behaviour analysis.

Similarly, with the wide variety of skills that are necessary in the applied field there could be gambits in Precision Teaching, Shaping, Stimulus Control, Stimulus Equivalence etc., that allow teachers to do more that talk about these issues, but actually engage students by working with real behaviour in class and along with a guided discussion of any associated epistemological issues. A manual of gambits could also contain details on how to access digital software for running practicals in basic learning principles. Teaching gambits might also inoculate students from becoming merely technicians who can follow protocols but who are not equipped to develop the science further.

\section{Supporting service users with assistive and behavioural technology}

ABA-based interventions are characterised by individualised service delivery in various settings like centres, family homes, communities and schools and by data-based decision-making. Typical interventions include a wide range of techniques usually applied in one-to-one or small group sessions. ABA-based services are usually designed around three levels of certification that the Behavior Analyst Certification Board ${ }^{\circledR}$ (BACBs) has established as a de facto international standard. Although, these are not legally or universally 
recognised in Europe, a growing number of universities across Europe provide BACB verified course sequences that are based on these standards and increasingly these courses utilise the teaching methods mentioned earlier.

The general aim of the BACB was to establish procedures for developing standards that (a) align with best practices in the credentialing industry and (b) are legally defensible in the USA (American National Standards Institute, 2016; Institute for Credentialing EXcellence, 2016). The vision behind these standards is to have a Masters level qualified manager responsible for interventions and other professionals at an assistant or technical level, who implement the procedures designed by the manager. The application of this system can vary from conteXt to conteXt and from country to country. In essence, the aim is to ensure that the various agencies, for example those who deal with a child's education and habilitation, have a centralised and coordinated way for monitoring the service user's progress and for using data-based decisions when designing interventions. Although the BACB credentialing system is not free from criticism (e.g., Carr, Nosik, \& DeLeon, 2017; Leaf et al. 2016), where it is recognised it ensures that providers of behaviour analysis services are qualified to deliver those services to clients. The professional figures involved and their roles generally include the following:

A senior behaviour analyst consultant, who is the case manager and supervisor, and who assesses the client's needs, designs the intervention and continuously evaluates the results. S/he is a Masters level Board Certified Behaviour Analyst (BCBA) who provides services that are consistent with $A B A$ dimensions. In addition, $s /$ he provides supervision to any Board Certified assistant Behaviour Analyst (BCaBA) or Registered Behavioural Technician (RBT), who is implementing the planned programmes. An undergraduate level $\mathrm{BCaBA}$ who helps with designing and implementing programmes and interventions, and also oversees programmes and interventions implemented by RBTs, and meets the team on a regular basis. BCaBAs are bachelor level professionals who work under the supervision of a BCBA.

A pre-degree level RBT who is a paraprofessional whose primary responsibility is to directly implement the programmes with the child and collect data under the supervision of the BCBA. S/he has received basic training in ABA (no less than $40 \mathrm{hrs}$ ), and has passed a hands-on competency assessment, and a written eXam in the science of $A B A$.

In behaviour plans and publications of research, ABA procedures are described clearly and concisely so that everyone with training in this science may replicate and implement them accurately. This basic feature of behavioural technology fosters not only replicability and improvement in procedures so that interventions become more effective and efficient, but offers clear algorithm-like description of procedures and settings that facilitate creating educational ABA-based software (Presti, Premarini, Leuzzi, Di Blasi, \& Squatrito, 2017). Effectiveness is also related to the integrity of interventions (Gresham, 1989; Truscott, Richardson, Cohen, Frank, \& Palmeri, 2003), in other words, the accuracy and consistency with which each element of any intervention plan is implemented. Failure to protect the integrity of interventions threatens their internal validity (Gresham, Gansle \& Noell, 1993), although this can be avoided by using specifically designed software.

Behavioural technological, data-based decision making, and procedural integrity/fidelity are the cornerstones on the path to using other technologies in learning 
settings, something which was pioneered by Skinner (1958) at the dawn of the computer revolution. When designing teaching material for programmed learning he listed several criteria:

The learner must be actively engaged with the material.

The instructional process should be self-paced.

Mastery criteria should prevent the learner from progressing without having mastered the prerequisites for the neXt step.

When possible, composing a response is to be preferred to selecting one.

Automated prompting should also be present and eventually faded to evoke the correct student response.

Consistent and immediate feedback should be provided and be individualised.

A curriculum should be tailored in steps large enough to reflect the learner's progress while promoting quick advancement yet small enough so that learners do not fail at any step.

These characteristics are highly relevant to computer-based teaching technologies, possibly magnified through the interconnection offered by networks and the Internet-ofthings (IOT). Despite his careful analysis, experimental data, and study on overcoming the difficulties of implementing a curriculum on computers, Skinner's approach to teaching machines was hijacked by cognitive and constructivist assumptions that underpin much of software production and instructional design (Johnson, 2014). Of course, quality control in software development, is vitally important. Digital applications that are founded on research-based strategies (Embry \& Biglan, 2008) should be given preference over those where no empirical evidence is collected or evidence is collected after 'sales'.

The "love story" between cognitive oriented scientists and computers contributed to the so called "cognitive revolution". This dominance was caused, at least partially, by the misconceptions mentioned earlier, that include the use of technical language being perceived as jargonistic or inaccessible. Although precise and useful in basic and applied science conteXts, in multidisciplinary and other collaborative conteXts the use of scientific terminology might interfere with dissemination (Critchfield et al. 2017; Skinner, 1981; Vyse, 2013).

Digital technologies can target a wide range of educational needs and individual skills. There are at least two areas in which technology can be implemented within the conteXt of ABA-based interventions, including animations and $Q R$ codes mentioned earlier.

Technology assisted curricula

Technology for programme maintenance and data collection

Technology assisted curricula. Children diagnosed with autism tend to prefer computer-based activities more than other non-technology-based activities (Costantin, Johnson, Smith, Lengyel, \& Brosnan, 2017) and the great majority of research on technology assisted curricula stems from frameworks or theories other than ABA. For eXample, an increase in social skills in children diagnosed with autism was observed with the use of technology-supported interactive social stories, which make it simple to integrate audio and teXtual information (Sani-Bozkurt, Vuran, \& Akbulut, 2017). At the same time, Malinverni, Mora-Guiard, Padillo, Valero and Hervas (2016) developed the kinect-based game, Pico's 
adventures, which successfully enhanced social skills in children. Neely, Rispoli, Camarg, Davis, and Boles (2012) showed that challenging behaviour can be reduced with the use of an iPad-based software, which seemed to be more effective to other strategies.

Wang, Laffey, Xing, Galyen and Stichter (2017) focused on verbal and non-verbal social interaction using the iSocial curriculum. After creating their own avatar and interacting virtually with peers, children with autism showed a reduction in inappropriate verbal activity and an increase in functional social interactions. However, there was no increase in joint attention (Srinivasan, Eigsti, Gifford, \& Bhat, 2016), eye contact, and emotion recognition, that was found when using social robots, such as IRobiQ and CARO, in therapy (Yun, Kim, Choi, \& Park, 2016). Srinivasan, Park, Neelly, and Bhat (2015) also observed a reduction in disruptive behavioural patterns using robot-based therapies. Taheri, Meghdari, Alemi, and Pouretemad (2017) showed how two social robots could engage individuals with autism in different individual/group imitation and joint attention tasks when used in a compleX social interactional conteXt that included two high-functioning individuals, their parents, a therapist, and a robot operator. Improvement in social skills, social participation/avoidance, and detrimental social behaviour were observed. Moreover, joint attention, gaze scores toward the robot, and verbal communications increased significantly over intervention time.

Digital technology also has been used to develop motor and language skills. For eXample, a video-modelling app (e.g., EXercise Buddy Application) was effective in promoting different motor tasks (Savage, Taber-Doughty, Brodhead, \& Bouck, 2017; Bittner, Rigby, Silliman-French, Nichols, \& Dillon, 2017). Earlier, Cardon (2012) had used video modelling-based imitation training successfully. Video-modelling (Nikipolous \& Keenan, 2006), delivered through various software and devices (e.g., iPad, EBapp, CRA), were shown to be useful also in developing academics, e.g., math skills (Cardon, 2012; Yakubova, Hughes, \& Shinaberry, 2016; Bittner, Rigby, Silliman-French, Nichols, \& Dillon, 2017; Savage, Taber-Doughty, Brodhead, \& Bouck, 2017).

Higher cognitive areas such as language, math and writing have also benefited from digital technology. Speech-generating devices (e.g., CompuThera Program, Language Master, ProLoquo2Go, GoTalk4+, software First Author) have been used successfully to promote manding in children diagnosed with autism (Sigafoos, Lancioni, O'Reilly, Achmadi, Stevens et al., 2013; Waddington, Sigafoos, Lancioni, O'Reilly, van der Meer, et al., 2014; Fteiha, 2017; Thiermann-Bourque, McGuff, \& Goldstein, 2017;). Presti, Messina, Mongelli, Sireci, and Collotta (2017) created and tested a Learning Management System to implement training based on stimulus equivalence to teach reading skills to autistic and dysleXic individuals. Other academic learning has also been targeted (Guldberg, Parsons, PorayskaPomsta, \& Keay-Bright, 2017; Hampshire \& Allred, 2018; Kagohara, van der Meer, Ramdoss, O'Reilly, Lancioni, et al., 2013), including writing skills with First Author Software (AsaroSaddler, KnoX, Meredith, \& Akhmedjanova, 2015) and math reasoning abilities with LEMA (Learning Environment on Mathematics for Autistic Children) (Santos, Breda, \& Almeida, 2017).

Obviously, digital technology that is based on ABA can be programmed specifically so as to tailor curricula to the functional skills level, learning pace, and motivating operations and reinforcers relevant for each child. In fact, for some children computer-delivered praise and prompts increased performance, including listening to, comprehending, or reading a story, physical activity, and problem-solving during task completion, and/or decreased challenging behaviour (Costantin, Johnson, Smith, Lengyel, \& Brosnan, 2017; Savage, Taber- 
Doughty, Brodhead, \& Bouck, 2017; Van Laarhoven, Carreon, Bonneau, \& Lagerhausen, 2018).

Although, a review of comparative studies between different models of software is outside the scope of this paper, differences emerge from the interactional designs that are generated through this individually tailored approach to learning. For eXample, ABCD SW is a web-based application that runs on any device with a browser connected to the internet (Artoni, Bastiani, Buzzi, Buzzi, Curzio, Pelagatti, \& Senette 2018) that aims to enable caregivers to use it at home with their children, under supervision, in order to reduce the cost of $A B A$-based interventions. $A B C D S W$ is mainly organised around discriminative stimuli in the form of audio-visual training using pictures and words, tact training with pictures, and matching-to-sample trainings with picture-to-picture, picture-to-word, word-to-picture and word-to-word protocols. The software adapts to the child's behavioural changes along the curriculum, offering errorless procedures, and mastery criteria levels. In addition, it includes some personalization such as the pictures used so that a child can be trained with material to which he or she is spontaneously attracted.

A more articulated bottom-up approach has been used by the designers of TOBY (Venkatesh, Phung, Duong, Greenhill, \& Adams 2013). Like ABCD SW, TOBY aims to simplify delivery of programmes for parents who are involved in ABA based interventions, helping with some of the most time-consuming aspects related to preparing materials for sessions and keeping records of the child's responses and progress. TOBY offers parents a way to deliver training to their children across three procedures: matching, imitation and Natural Environment Training (NET). The syllabus covers four major skill areas: perception and discrimination of sensory cues, motor and vocal imitation, listener and speaker patterns, and interpersonal skills, such as joint-attention. By teaching parents some basics skills in $A B A, T O B Y$ also aims to be a tool to develop a parenting repertoire applicable to other crucial areas of their child's development that cannot be handled by a computer.

Technology for program maintenance and data collection. The precision involved in the delivery of ABA-based services requires careful preparation of materials and clear guidelines for data collection. Technology can be used to keep a repository of curricula and track behavioural advances precisely. One good eXample is the Autism Curriculum Encyclopedia (ACE) web-based curriculum (www.acenecc.org) developed at The New England Center for Children (NECC). The software started as a tool for NECC employees to decrease the time needed to prepare material and design the session plans in a way that is easy to follow. It puts an emphasis on the consistency attainable across different settings by the skilled and trained users. The curriculum includes thousands of plans and offers a description of materials, procedures, mastery criteria and all the details needed to deliver personalised trainings to individuals with disabilities between ages 3 and 22 years old. The academic and non-academic skills covered by ACE range from discrimination, verbal behaviour, social skills, self-help, health and safety, recreation, to physical education, community, vocational, and transition to adulthood. Each domain has a variety of lessons that target different skills relating to each area. ACE offers a platform for direct in-session data collection, with the help of specifically programmed menus that alleviate the usual paper and pencil work and subsequent transfer to graph and analyse data. Occurrences of challenging behaviour can also be recorded or videoed while they occur for later evaluation. ACE users are limited to $B C B A s$, but ACE can be used across many settings, schools, clinics, homes, and research centres. 
Rethink (www.rethinkfirst.com) is another web-based ABA programme used to teach individuals diagnosed with autism. In contrast to $A C E$, it also addresses training of parents, administrators, and teachers on how to implement ABA-based procedures with their children and students. It is built around 1,500 video lessons that target a number of domains, each described in its subset of skills, including pre-academic, academic, social/emotional, daily living, motor, play/leisure, listener and speaker verbal behaviour. Each session is described in significant levels of detail, that include materials, objectives, teaching steps/task analysis, generalization techniques, troubleshooting strategies, among others. Rethink contains three different assessments (i.e., abilities, inclusion, and transition) that evaluate the student's current level of functioning in order for the software to select the appropriate plans.

\section{Smart Spaces for ABA: A conceptual frame for ABA-based services.}

Traditionally, ABA providers have relied on paper and pen-based materials to deliver training and record in-session progress. This usually incurs significant preparation costs and can also be poorly implemented in practice. The structured progression procedures, recordkeeping, and stimulus-based learning, that are typical for ABA-based interventions are perfectly suitable for computer-based delivery. However, most of the software has been developed as stand-alone solutions in an era were cloud-based services were not available.

The cloud makes it possible to adopt a much more centralised vision that facilitates coordination between agencies and service delivery companies across environments, schools, and families and therefore to maXimise access to natural reinforcers. Software designed with a closed architecture in mind mainly served the scopes of the authors without considering the more general ABA-based ecosystem. In order to deliver evidence-based services, the larger ecosystem around the child and his family need to be addressed, including governmental and non-governmental stakeholders. There is a need for an Operating System (OS) that can integrate technology assisted curricula and programmes for maintenance and data collection in a coherent way and that allows third parties to write software or build hardware that allows smooth data transmission.

Smart Space for $A B A$ is a concept that accommodates such an ecosystem. It is a virtual space for the implementation of $A B A$-based interventions that does not necessarily overlap or coincide with a specific physical place but connects those places in the life of a child in which natural interactions take place. In these physical places, modern technology offers a chance to monitor the child's development with different tools to record progress and to verify consistency in the application of ABA-based programmes. The child can interact with specifically, programmed hardware and avail of interactions that enhance their cognitive, emotional, social, and linguistic skills. These programmes also can assist skilled or unskilled adults (technicians, parents, relatives, family to name a few) to deliver ABA-based interventions. In addition, other stakeholders can be connected, with appropriate permission, so as to monitor the individual progress and collaborate in the intervention plan.

As shown in Figure 8, the Smart Space for ABA framework is identified by the set of physical places brought together by a technological infrastructure that allows the programming of interventions and receives inputs from different tools that collect data or provide learning programmes. The Smart Space connects the various environments in which the child lives and learns, and it permits those who deliver an ABA-based programme to resume from the point where the previous educational interaction ended, whether this 
happened in the same environment, or in another environment. For eXample, at school the child may have worked with the teacher on a programme to learn colours, perhaps using an iPad. At home, the behavioural technician or a family member continues this work from the level where the special education teacher left off. By taking into account the child's learning progress in the various areas of intervention, the Smart Space system facilitates the transition between professionals, programmes and environments. Each actor in the Smart Space is informed of progress and can, in turn, feed information into the system. The ABA consultant who is the custodian of the educational and rehabilitation project can monitor in real time the learning curves and implement new programmes or adjustments to eXisting programmes on the basis of the data received.

The technological backbone of a Smart Space for $A B A$ is a database for keeping track of the progress in the ABA programming. Currently, Presti is working on a database called ADA (ABA - Data management for Autism). It records each response unit for each session so as to have a precise and highly specific trace of the child's progress for each programme, whether be it through the aid of an IT tool, or through more traditional pen and paper methods. A usual relatively intensive programme for a child with autism involves around 1012 ABA-based programmes covering a wide range of linguistic, cognitive, and social abilities. The archive is constructed in such a way as to follow any developmental path of cognitive and linguistic abilities as defined by evidence-based criteria and individualised educational curricula. It is more than a traditional medical record and closer to a guide to planning and monitoring progress, and where the shared knowledge of the community of users can be used to build and validate evidence-based practices.

$A D A$ is conceptualised as an OS for the ABA ecosystem and is programmed to receive input from a number of different devices. The ones tested so far include: Smart Room (Figure 9), an interactive platform based on "Project Mapping" and an "Interactive wall" that transforms a whole therapy room, including furniture and objects, into an interactive fullscale touch device. The idea is to create a space that can guide the child to the recognition of the world and the use of the objects of his/her world. It can make use of 1 to 6 projectors and cameras positioned according to the size of the room and depth cameras are used to recognize people inside the room and to capture interactions between projected objects and real people. It can be used for space recognition, motor skills, social interaction, interaction in safe simulations of potentially dangerous environments for the child. Moreover, the use of walls to create an immersive reality allows for the reproduction of life size environments and situations in which to verify the generalisation of learning.

Social Robot: The use of humanoid robots (Figure 10) stimulates social interaction. At the same time, this technology can acquire objective metrics, since these products are equipped with sensors such as cameras, ultrasounds, etc., and have the possibility to replicate facial expressions for imitation or to capture attention. Imitation-based therapies can improve the propensity to imitate certain facial expressions and the robot can act as a model and guide the child's interaction with environmental stimuli or other types of stimuli that he/she can propose. The use of robots makes it possible to produce standardised stimuli and an objective assessment of the child's responses (through the measurement of ocular attachment time, proXemics, facial eXpressions, etc.). Children diagnosed with autism are particularly sensitive to the expressions of the robot because they have a more standardised and simplified components that can allow a phase of learning in which there is a transition to the more compleX and articulated expressions of adults, which these children have eXtreme difficulty in recognising. Social robots like Milo (www.robots4autism.com) can 
be also used to deliver training in conjunction with a tablet-based software. In Figure 12 an equivalence-based software was used to teach a child with autism to match audio-to-visual stimuli (Sidman \& Tailby, 1982). The Robot was programmed to present the audio sample, to prompt the response with a small screen on the chest showing the stimuli that matched comparisons on the iPad, during an errorless procedure phase, and to offer contingent reinforcers after correct matching.

Apps for computer or tablets: The use of software for ABA has been the most consolidated aspect of technological developments for over thirty years. In this model, apps are connected additionally to the data archive and the educational programming tools contained within it. The laptop and mobile platforms offer fleXibility of use and smooth transitions from one environment to the other because the child can pick up from where he/she left off, thanks to data transmission from ADA to any app.

Ambient Technology: Applying ABA programmes is not simple and requires high degree of accuracy in delivering effective programmes tailored to the needs of each child. For parents and family members who want to offer learning opportunities to their children, being able to replicate sophisticated procedures is not easy and they run the risk being counterproductive for attaining educational goals. The ambient technology is a combination of hardware (motion detection) and software that is able to follow the movements of a mentor and child and assist the tutor in carrying out an ABA-based programmes. It offers instructions on randomisation of the stimulus items, feedback programs, reinforcers, and on recording the child's responses.

Virtual and augmented reality: ABA-based programmes can leverage the opportunity of superimposing virtual stimuli to reality (augmented reality) in ways that help promote adaptive behaviour. In addition, stimuli can progressively be faded so that environmental and natural stimuli can eXert increasing levels of control over that behaviour. Virtual environments, in addition, can be used to teach compleX new behaviour that can be practiced in the safety of the virtual world before being introduced to the natural environment.

Data input: A series of tools, from a simple laptop to a tablet or smart-phone, or even tools built ad hoc, can be designed to feed into the data archive directly and track the behavioural progress in structured and non-structured learning situations.

\section{Conclusion}

In any discussion of teaching, it would be at best naïve, and at worst irresponsible, to ignore the technological requirements needed to address the social/conteXtual issues described above. If they are to avoid building castles in the air, behaviour analysts in Europe need to use their science in a concerted way to advocate for ABA. Without the use of behavioural technology for advocacy there will be little uptake of ABA-based interventions for autism or other areas in Europe, no matter how persuasive the database of effectiveness continues to be (e.g., Cooper, Heron, \& Heward, 2007; Green, 1996; Luce, Green, \& Maurice, 1996). Higher Education pedagogues and academics have a responsibility to prepare students for practice and that includes teaching them about how to deal with the obstacles they are likely to encounter in their professional lives (Gillen \& Keenan, 2017). Given that many of the students will work in the field of autism, they need to learn about the value of using the science to build and nurture strategic partnerships between parents and other professionals (Taylor, Leblanc, \& Nosik, 2018). 
In terms of developing different kinds of teaching material, professional organisations could solicit and collate a range of teaching gambits to cover a wide variety of issues that include philosophical, experimental and applied branches of behaviour analysis. The conteXt in which behaviour analysis is taught in Europe demands that eXisting misrepresentations are confronted directly. A manual of practical teaching eXercises would be helpful particularly to new teachers of behaviour analysis. QR codes would augment this kind of manual, as particular issues can be shown and practiced at length in vivo and on video. Of course, there are a number of issues that arise in creating such a manual. Editors might demand evidence for the effectiveness of any practicals that are submitted for inclusion. However, the same issue arises for any teXtbook; even most eminent scholars such as Skinner were not asked for evidence on the value of their writing before it was accepted for publication. A collection of teaching gambits would be a collection of creative ideas to stimulate others into being creative in their teaching. Of course, once published, one could then collect data on the effectiveness of particular gambits, but creativity should be given a chance in the first instance. Similar issues arise in the design of other discriminative stimuli; a designer needs to know their audience. Behaviour analysts need to remember that we do not teach in a vacuum, and that perhaps carelessness in communication to date has contributed to some of the obstacles encountered.

Importantly therefore, technology could also be used for communication and understanding amongst staff and students. This is not to be confused with communicationbased technology tools which are covered extensively in this paper, but the use of technology to improve communication among team members serving a client, programme or school staff and the families being served, other service providers. Cloud-based technology offers new opportunities to bring ABA-based interventions for children diagnosed with autism to a highly sophisticated level. Smart Space addresses these issues, namely diffusion, training, implementing programmes, including monitoring the intervention, supervision and communication with staff, parents, school, National Health Systems, and other agencies involved in the intervention with individuals diagnosed with autism. ABA-based services might benefit in terms of continuity and the integrity of interventions, effectiveness and cost reduction, and offer more personalised trainings to fit the child's behavioural profile. Smart Space can increase the opportunity for analysis at both molecular and molar levels and allow for the analysis of interlocking contingencies across individuals' behaviour and settings. It can eXtend the precision of measurement of effectiveness of ABA-based procedures. It can help understanding better the behavioural variables related to the integrity of interventions. It can generate predictive data on the way specific child characteristics (age, level of function etc.) and thereby influence the design of a particular ABA-based programme, thus improving data-based decision.

The use of technology (e.g., telehealth, Ferguson et al., 2018) also helps in the delivery and supervision of services in underserved communities and countries, where certified behaviour analysts may not be available on site. A framework that includes behavioural as well as digital and cloud-based technologies can generate far-reaching changes (Escobar \& Twyman, 2014). This kind of framework has the potential to herald a behavioural cusp (Rosales-Ruiz \& Baer, 1997; Twyman, 2011) for achieving wide and accurate dissemination of $A B A$ in Europe.

\section{Ethics Statement:}


The research reported here has been approved by the appropriate institutional research ethics committee and have been performed in accordance with the ethical standards as laid down in the 1964 Declaration of Helsinki and its later amendments or comparable ethical standards.

Statement about conflict of interest:

The authors declare no conflict of interest.

\section{References}

AAAS (2018). American Association for the Advancement of Science: Workshop on Advocacy in Science. Retrieved April 7, 2018, from https://www.aaas.org/page/srhrl-pastprojects-workshop-advocacy-science.

Arton, S., Bastiani, L., Buzzi, M.C., Buzzi, M., Curzio, O., Pelegatti, S., \& Senette, C. (2018). Technology-enhanced ABA intervention in children with autism: A pilot study. Universal Access in the Information Society, 17(1), 191-210.

Asaro-Saddler, K., KnoX, H. M., Meredith, H., \& Akhmedjanova, D. (2015). Using technology to support students with autism spectrum disorders in the writing process: A pilot study. Insights into Learning Disabilities, 12, 103-119.

Autism Speaks. (2014). State Initiatives. Retrieved July 21, 2014, from http://www.autismspeaks.org/advocacy/states

BACB. (2018). Behavior Analyst Certification Board. Retrieved April 3, 2018, from https://www.bacb.com

Baron-Cohen, S. (2014). What scientific idea is ready for retirement? Radical behaviourism. Retrieved April 2, 2018, from https://www.edge.org/response-detail/25473

Baum, W. M. (2011). No need for private events in a science of behavior: Response to commentaries. The Behavior Analyst, 34, 237-244.

Bittner, M. D., Rigby, B. R., Silliman-French, L., Nichols, D. L., \& Dillon, S. R. (2017). Use of technology to facilitate physical activity in children with autism spectrum disorder: a pilot study. Physiology \& Behavior, 177, 242-246.

Cardon, T. A. (2012). Teaching caregivers to implement video modelling imitation training via iPad for their children with autism. Research in Autism Spectrum Disorders, 6, 13891400.

Carr, J. E., Nosik, M. R., \& DeLeon, I. G. (2017). The Registered Behavior Technician ${ }^{\text {TM }}$ credential: A response to Leaf et al. (2017). Behavior Analysis Practice, 10, 164-166.

Cooper J. O, Heron T. E, Heward W. L. (2007). Applied behavior analysis (2nd ed.). Upper Saddle River, NJ: Pearson.

Costantin, A., Johnson, H., Smith, E., Lengyel, D., \& Brosnan, M. (2017). Designing computerbased rewards with and for children with autism spectrum disorder and/or intellectual disability. Computers in Human Behavior, 75, 404-414.

Chritchfield, T. S. \& Reed, D. D. (2017). The fuzzy concept of applied behavior analysis research. The Behavior Analyst, 40, 123-159.

Dillenburger, K., McKerr, L., \& Jordan, J.-A. (2014a). Lost in translation: Public policies, evidence-based practice, and Autism Spectrum Disorder. International Journal of Disability, Development and Education, 61(2), 134-151. 
http://doi.org/10.1080/1034912X.2014.905059

Embry, D. D., \& Biglan, A. (2008). Evidence-based kernels: Fundamental units of behavioral influence. Clinical Child and Family Psychology Review, 11(3), 75-113.

http://doi.org/10.1007/s10567-008-0036-X

Escobar, R. \& Twyman, J. S. (2014). Behavior anlysis and technology. Revista MeXicana de Análisis de la Conducta, 40, pp. 1-2

European Commission. (2018). Database of regulated professions. Retrieved April 14, 2018, from https://ec.europa.eu/growth/single-market/services/free-movementprofessionals/regulated-professions-database_en

European Parliament. (2005). Directive 2005/36/EC of the European Parliament and of the Council on the recognition of professional qualifications. Retrieved September 7, 2005, from http://eur-leX.europa.eu/legalcontent/EN/TXT/PDF/?uri=CELEX:32005L0036\&from=EN

Ferguson, J., Craig, E. A., \& Dounavi, K. (2018). Telehealth as a Model for Providing Behaviour Analytic Interventions to Individuals with Autism Spectrum Disorder: A Systematic Review. Journal of Autism and Developmental Disorders.

DOI: $10.1007 / \mathrm{s} 10803-018-3724-5$

Freeman, S. (2003). Science for sale in the autism wars: Medically necessary autism treatment, the court battle for health insurance, and why health technology academics are enemy number one. Bellingham, WA: SKF Books.

Fteiha, M.A. (2017). Effectiveness of assistive technology in enhancing language skills for children with autism. International Journal of Developmental Disabilities, 63, 36-44.

Gandalovicova, J. (2016). The arrival of ABA in the Czech Republic. European Association for Behaviour Analysis Newsletter, December. Retrieved April 14, 2018, from http://www.europeanaba.org/

Gillen, E., \& Keenan, M. (2017). When policy decisions for autism treatment in Europe are hijacked by a category mistake. Psichologija Praktikai, 56, 72-78. Retrieved April 14, 2018, from www.journals.vu.It/psichologija/article/download/11532/10143

Green, G. (1996). Evaluating claims about treatments for autism. In C. Maurice, G. E. Green, \& S. C. Luce (Eds.), Behavioral intervention for young children with autism: a manual for parents and professionals (pp. 15-28). Champaign, IL: Pro-Ed.

Gresham, F. M. (1989). Assessment of treatment integrity in school consultation and prereferral intervention. School Psychology Review, 18, 37-50.

Gresham, F. M., Gansle, K.A., Noel, G.H. (1993). Treatment integrity in applied behavior analysis with children. Journal of Applied Behavior Analysis, 26, 257-263

Greydanus, D. E., Pratt, H. D., Richard Spates, C., \& Blake-Dreher, A. E., Greydanus-Gearhart, M. a, \& Patel, D. R. (2003). Corporal punishment in schools. Journal of Adolescent Health, 32(5), 385-393. http://doi.org/10.1016/S1054-139X(03)00042-9

Guldberg, K., Parsons, S., Porayska-Pomsta, K., \& Keay-Bright, W. (2017). Challenging the knowledge-transfer orthodoXy: Knowledge co-construction in technology-enhanced learning for children with autism. British Educational Research Journal, 43, 394-413.

Gunn, J. (2010). Dr Harold Frederick Shipman: An enigma. Criminal Behaviour and Mental Health. 20(3), 190-198. http://doi.org/10.1002/cbm.768

Hampshire, P. K., \& Allred, K. W. (2018). A parent-implemented, technology-mediated approach to increasing self-management homework skills in middle school students with autism. EXcepitionality, 26(2), 119-136. 
Helton, M. R., \& Alber-Morgan, S. R. (2018). Helping parents understand applied behavior analysis: Creating a parent guide in 10 Steps. Behavior Analysis in Practice, 11(4), 496503.

Howlin, P. (2013). 70 Years of Autism research: How far have we come? Autism Europe Newsletter, Dec. Retrieved Jan. 14, 2014, http://www.autismeurope.org/blog/category/link-magazine/

Isituto Superiore di Sanità (2015). Linea Guida 21. II trattamento dei disturbi dello spettro autistico nei bambini e negli adolescenti. Rome (Italy): Sistema Nazionale delle Linee Guida

Institute for Credentialing EXcellence (2016). ST NCCA Standards for the Accreditation of Certification. Retrieved June 16, 2018 from http://www.credentialingeXcellence.org/p/pr/vi/prodid=169

Johnson, W. B. (2014). Mentoring in psychology education and training: A mentoring relationship contin- uum model. In W. B. Johnson \& N. J. Kaslow (Eds.), The OXford handbook of education and training in professional psychology. New York: OXford University Press.

Jordan, R. (2001). Parents' Education as Autism Therapists: Applied Behaviour Analysis in ConteXt. By M. Keenan, K. Kerr \& K. Dillenburger. Jessica Kingsley Publishers, London. pp. 175. f13.95 (pb). Journal of Child Psychology and Psychiatry, 42(3), 421-423. https://doi.org/10.1111/1469-7610.00735

Kagohara, D. M., van der Meer, L., Ramdoss, S., O’Reilly, M. F., Lancioni, G. E., Davis, T. N., Rispoli, M., Lang, R., Marschik, P. B., Sutherland, D., Green,V. A., \& Sigafoos, J. (2013). Using iPods and iPads in teaching programs for individuals with developmental disabilitie: a systematic review. Research in Developmental Disabilities, 34, 147-156.

Keenan, M. (2015). Private Events (1 and 2) and Black BoX. Retrieved June 16, 2018 from http://youtu.be/MH2I1AZbYEU (Private Events 1); http://youtu.be/2II6YXhceUg (Private Events 2); https://youtu.be/ISuVGWhH8ZU (Black BoX).

Keenan, M. (2016). The scientific image in behavior analysis. The Behavior Analyst, 39, 7-8. http://doi.org/10.1007/s40614-016-0059-4

Keenan, M., \& Dillenburger, K. (2000). Images of behavior analysis: The Shaping Game and the Behavioral Stream. Behavior and Social Issues, (10), 19-38.

Keenan, M., \& Dillenburger, K. (2014). Behaviour analysis: A primer. Retrieved January 30, 2015, from https://itunes.apple.com/gb/book/behaviour-analysis-aprimer/id564540452?mt=11

Keenan, M., \& Dillenburger, K. (2018). How 'Fake News' affects autism policy. Societies. 8(2), 29. http://www.mdpi.com/2075-4698/8/2/29

Keenan, M., Dillenburger, K., Moderato, P., \& Röttgers, H.-R. (2010). Science for sale: But at what price? Behavior and Social Issues, 19, 126. http://doi.org/10.5210/bsi.v19i0.2879

Keenan, M., Dillenburger, K., Röttgers, H.-R., Dounavi, K., Jónsdóttir, S. L., Moderato, P., Schenk, J.A.M., Roll-Pettersson, L., \& Martin, N. (2015). Autism and ABA: The gulf between North America and Europe. Review Journal of Autism and Developmental Disorders, 2(2), 167-183. http://doi.org/10.1007/s40489-014-0045-2

Kelly, M., Martin, N., Dillenburger, K., Kelly, A., \& Miller, M. M. (2018). Spreading the news: History, successes, challenges and the ethics of effective dissemination. Behavior Analysis in Practice, Retrieved Dec 18, 2018, from https://link.springer.com/article/10.1007/s40617-018-0238-8

Kupferstein, H. (2018). Evidence of increased PTSD symptoms in autistics eXposed to applied 
behavior analysis. Advances in Autism, 4(1), 19-29. http://doi.org/10.1108/AIA-082017-0016

Lau, M., Chai, J., Xu, Y.-Q., \& Shum, H.-Y. (2009). Face poser. ACM Transactions on Graphics, 29(1), 1-17. http://doi.org/10.1145/1640443.1640446

Layng, T. V. (2014). Learning science design and development requirements: An update of HendriX and Tiemann's "Designs for designers." MeXican Journal of Behavior Analysis, 40, 39-57. Retrieved Dec 18, 2018, from http://rmac-mX.org/wpcontent/uploads/2015/01/05.-T.-V.-Joe-Layng-39-57-corregido.pdf

Leaf, J. B., Kassardjian, A., Oppenheim-Leaf, M. L., Cihon, J. H., Taubman, M., Leaf, R., \& McEachin, J. (2016). Social Thinking ${ }^{\oplus}$ : Science, Pseudoscience, or Antiscience? Behavior Analysis in Practice, 9(2), 152-157. doi: 10.1007/s40617-016-0108-1

LedouX, S. (1987) EXpanding the Happy Few: A review of The Critical Years by Doris Durrel. Behavior Analysis and Social Action, 6, 1, 44-47. Retrieved Dec 18, 2018, from https://pdfs.semanticscholar.org/8e96/cd12e9ca111033d18838cf9cf7f6f8a99424.pdf

Luce, S. C., Green, G., \& Maurice, C. (1996). Behavioral intervention for young children with autism. Austin, TX, US: PRO-ED

Lupia, A. (2013). Communicating science in politicized environments. Proceedings of the National Academy of Sciences of the United States of America, 110(3), 1404814054. doi: 10.1073/pnas.1212726110

Malinverni, L., Mora-Guiard, J., Padillo, V., Valero, L., Hervas, A. (2017). An inclusive design approach for developing video games for children with autism spectrum disorder. Computers in Human Behavior, 71, 535-549.

McCormack, P. (2012). Story from the Republic of Ireland. The Current Repertoire Newsletter of the Cambridge Center for Behavioral Studies, 28(3), 2 \& 12-13.

McCormack, P. (2015). The role of teachers. Keynote address at 4th CBA Conference (2015): Multidisciplinary work and autism. $4^{\text {th }}$ Centre for Behaviour Analysis conference: Multidisciplinary work and autism, Queen's University Belfast. (Nov., 6).

Milton, D. (2012). The normalisation agenda and the psycho-emotional disablement of autistic people. Autonomy, the Critical Journal of Interdisciplinary Autism Studies, 1(1), 1. Retrieved June 16, 2018, from http://www.larryarnold.net/Autonomy/indeX.php/autonomy/article/view/AR3/21

Neely, L. B., Rispoli, M., Camarg, S., Davis, H., Boles, M. (2012). The effect of instructional use of an iPad on challenging behaviour and academic engagement for two student with autism. Research in Autism Spectrum Disorders, 7, 509-516.

NICE (2015) Challenging Behaviour and Learning Disabilities; Prevention and Interventions for People with Learning Disabilities whose Behaviour Challenges. NICE guideline; NG11. Retrieved August 4, 2017, from https://www.nice.org.uk/guidance/ng11

NICE. (2016). AppendiX B: stakeholder consultation comments table. Retrieved August 4, 2017, from https://www.nice.org.uk/guidance/cg138/evidence/appendiX-bstakeholder-consultation-comments-table-2603603055

PEAT. (2002). Northern Ireland Task Group Report on Autism: PEAT response. Retrieved December 2, 2017, from http://www.imagesforbehaviouranalysts.com/uploads/1/0/2/5/10258235/peatrespon se.pdf

Presti, G., Premarini, C., Leuzzi, M., Di Blasi, M. \& Squatrito, V. (2017). Recursiveness in learning processes: An analogy to help software development for ABA intervention for autistic kids. AIP Conference Proceedings 1906, 190013. 
https://doi.org/10.1063/1.5012476

Presti, G., Messina, C., Mongelli, F., Sireci, M. J., \& Collotta, M. (2017). Implementing software based on Relational Frame Theory to develop and increase relational cognitive skills. AIP Conference Proceedings 1906, 190012. https://doi.org/10.1063/1.5012475

Roll-Pettersson, L., Ala'i- Rosales, S., Keenan, M., \& Dillenburger, K. (2015). Teaching and learning technologies in Higher Education: Applied Behaviour Analysis and autism; "Necessity is the mother of invention." European Journal of Behavior Analysis, 11(2), 247-259. http://doi.org/10.1080/15021149.2010.11434349

Rosales-Ruiz, J. \& Baer, D.M. (1997). Behavioral cusps: A developmental and pragmatic concept for behavior analysis. Journal of Applied Behavior Analysis, 30(3), 533544, doi:10.1901/jaba.1997.30-533.

Sani-Bozkurt, S., Vuran, S., \& Akbulut, Y. (2017). Design and use of interactive social stories for children with autism spectrum disorder (ASD). Contemporary educational technology, 8, 1-25.

Santos, M. I., Breda, A., \& Almeida, A. M. (2017). Design approach of mathematics learning activities in a digital environment for children with autism spectrum disorders. Educational Technology Research and Development, 65(5), 1305-1323.

Savage, M. N., Taber-Doughty, T., Brodhead, M. T., \& Bouck, E. C. (2017). Increasing physical activity for adults with autism spectrum disorder: comparing in-person and technology delivered praise. Research in Developmental Disabilities, 73, 15-125.

Sigafoos, J., Lancioni, G. E., O’Reilly, M. F., Achmadi, D., Stevens, M., Roche, L., Kagohara, D. M., van der Meer, L., Sutherland, D., Lang, R., Marshik, P. B., McLay, L., Hodis, F., \& Green, V. A. (2013). Teaching two boys with autism spectrum disorders to request the continuation of toy play using iPad-based speech generating device. Research in Autism Spectrum Disorders, 7, 923-930.

Sidman, M. \& Tailby, W. (1982) Conditional discrimination vs. matching to sample: an expansion of the testing paradigm. Journal of the experimental Analysis of Behavior, 37(1), 5-22. doi: 10.1901/jeab.1982.37-5

Simple Steps. (2013). Simple Steps Autism: The online teaching platform for the treatment of Autism. Retrieved October 29, 2014, from www.simplestepsautism.com

Skinner, B. F. (1953). Science and human behaviour. Retrieved Dec, 18, 2018, from http://www.behaviorpedia.com/wpcontent/uploads/2013/01/Science_and_Human_Behavior.pdf

Skinner, B. F. (1958). Teaching Machines. American Association for the Advancement of Science. 128. 969-977.

Skinner, B. F. (1980). Notebooks. Upper Saddle River, NJ.: Prentice Hall.

Skinner, B. F. (1981). We happy few, but why so few? Paper presented at the meeting of the Association for Behavior Analysis, Milwaukee, WI.

Spinzy, Y., \& Cohen-Rappaport, G. (2016). Together we stand in the bottomless pit - When trauma hits the therapeutic dyad. Psychosis, 8(1), 88-92. http://doi.org/10.1080/17522439.2015.1052007

Srinivasan, S.M., Eigsti, I., Neelly, L., \& Bhat, A. (2016). The effect of embodied rhythm and robotic interventions on the spontaneus and responsive social attention patterns of children with autism spectrum disorder (ASD): a pilot randomized controlled trial. Research in Autism Spectrum Disorders, 27, 54-72. 
Srinivasan, S.M., Park, I.K., Neelly , L.B., \& Bhat, A.N. (2015). A comparison of the effect of rhythm and robotic interventions on repetitive behaviors and affective states of children with autism spectrum disorder (ASD). Research in Autism Spectrum Disorders, 18, 51-63.

STAMPPP. (2013). Science and the treatment of Autism: A multimedia package for parents and professionals. Retrieved February 6, 2015, from http://www.stamppp.com/

Taheri, A., Meghdari, A., Alemi, M., \& Pouretemad, H. (2018). Human-robot interaction in autism treatment: A case study on three pairs of autistic children as twins, siblings, and classmates. International Journal of Social Robotics, 10(1), 93-113.

Taylor, D. (2007). Death by PowerPoint. Developmental Medicine \& Child Neurology, 49(5), 395.

Taylor, B., LeBlanc, L. A., \& Nosik, M. (2018). Compassionate care in behavior analytic treatment: Can outcomes be enhanced by attending to relationships with caregivers? Behavior Analysis in Practice. https://doi.org/10.1007/s40617-018-00289-3

The Skeptical Advisor. (2014). Simon Baron-Cohen's fantastically false article on radical behaviorism: An eXample of valid, but false premises. Retrieved November 11, 2014, from http://theskepticaladvisor.wordpress.com/2014/01/21/simon-baron-cohensfantastically-false-article-on-radical-behavior-an-eXample-of-valid-but-false-premises/

The Westminster Commission on Autism. (2018). A spectrum of obstacles. An inquiry into access to healthcare for autistic people. Retrieved April 7, 2018, from https://westminsterautismcommission.files.wordpress.com/2016/03/ar1011_ncgautism-report-july-2016.pdf

Thiermann-Bourque, K. S., McGuff, S., \& Goldstein, H. (2017). Training peer partners to use a speech-generating device with classmates with autism spectrum disorder: eXploring communication outcomes across preschool conteXts. Journal of Speech, Language, and Hearing Research, 60, 2648-2662.

Unumb, L. (2013). Keynote address by Dr Lorri Unumb at Centre for Behaviour Analysis (QUB) conference. Retrieved June 16, 2018, from https://mediasite.qub.ac.uk/Mediasite/Play/564a563b432440b68375d102170c337a1d

Todd, J. T. (1987). The great power of steady misrepresentation: Behaviorism's presumed denial of instinct. The Behavior Analyst, 10, 117-118

Todd, J. T. \& Morris, E. K. (1983). Misconception and miseducation: Presentations of radical behaviorism in psychology teXtbooks. The Behavior Analyst, 6, 153-160.

Truscott, S. D., Richardson, R. D., Cohen, C., Frank, A. \& Palmeri, D. 2003. Does rational persuasion influence potential consultees? Psychology in the Schools, 40, 627-640.

Twyman, J. S. (2011). Emerging technologies and behavioural cusps: A new era for behaviour analysis? European Journal of Behaviour Analysis, 12(2), 461-482.

Van Laarhoven, T., Carreon, A., Bonneau, W., \& Lagerhausen, A. (2018). Comparing mobile technologies for teaching vocational skills to individuals with autism spectrum disorder and/or intellectual disabilities using universally-designed prompting systems. Journal of Autism and Developmental Disorders, 48(7), 2516-2529

Venkatesh, S., Phung, D., Duong, T., Greenhill, S., \& Adams, B. (2013). TOBY: Early intervention in autism through technology. CHI 2013: Changing Perspective, 3187-3196.

Virués-Ortega, J. \& Yu, C. T. (2018). The process of knowledge translation in Behavior Analysis. Operants, 1, 8-9.

Vyse, S. (2013). Believing in magic: The psychology of superstition-updated edition. Oxford: University Press. 
Waddington, H., Sigafoos, J., Lancioni, G. E., O'Reilly, M. F., van der Meer, L., Carnett, A., Stevens, M., Roche, L., Hodis, F., Green, V. A., Sutherland, D., Lang, R., \& Marschik, P. B. (2014). Three children with autism spectrum disorder learn to perform a three-step communication sequence using an iPad- based speech-generating device. International Journal of Developmental Neuroscience, 39, 59-67.

Wang, X., Laffey, J., Xing, W., Galyen, K., \& Stichter, J. (2017). Fostering verbal and nonverbal social interactions in a $3 \mathrm{D}$ collaborative virtual learning environment: A case study of youth with Autism Spectrum Disorders learning social competence in iSocial. Educational Technology Research and Development, 65(4), 1015-1039.

Westminster Commission on Autism. (2018). A spectrum of harmful interventions for autism. Retrieved April 15, 2018, from https://thegivingtreefoundation.co.uk/images/pages/westminster/Final_edit_A_spectr um_of_harmful_interventions_for_autism.pdf

Yakubova, G., Hughes, E. M., \& Shinaberry, M. (2016). Learning with technology: video modeling with concrete- representational-abstract sequencing for students with autism spectrum disorder. Journal of Autism and Developmental Disorders, 46, 23492362.

Yun, S., Kim, H., Choi, J., \& Park, S. (2016). A robot-assisted behavioral intervention system for children with autism spectrum disorders. Robotic and Autonomous System, 76, 5867.

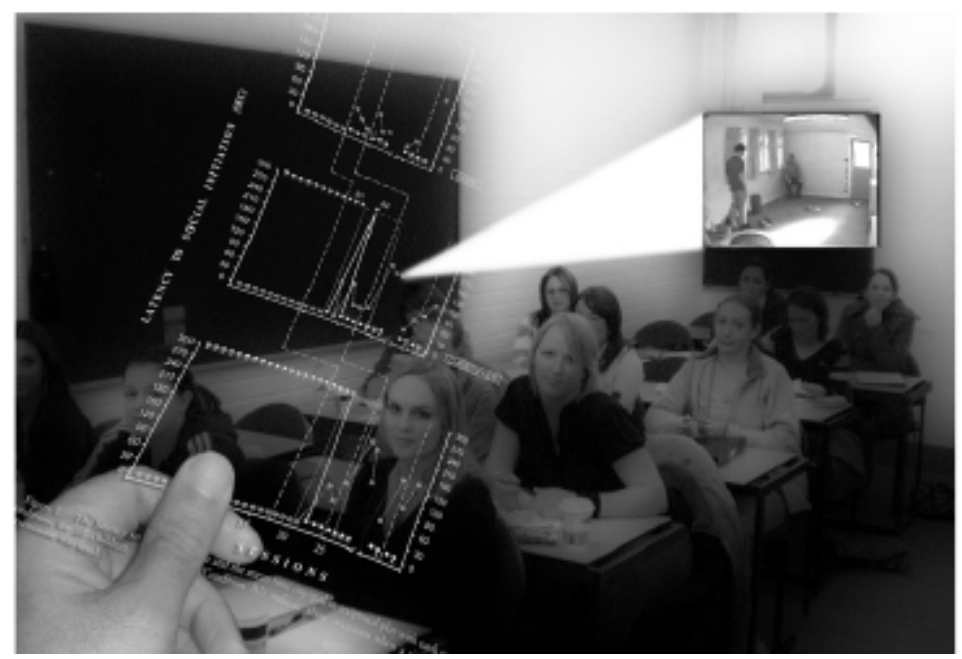

Figure 1. Animated data points on a PowerPoint slide. 


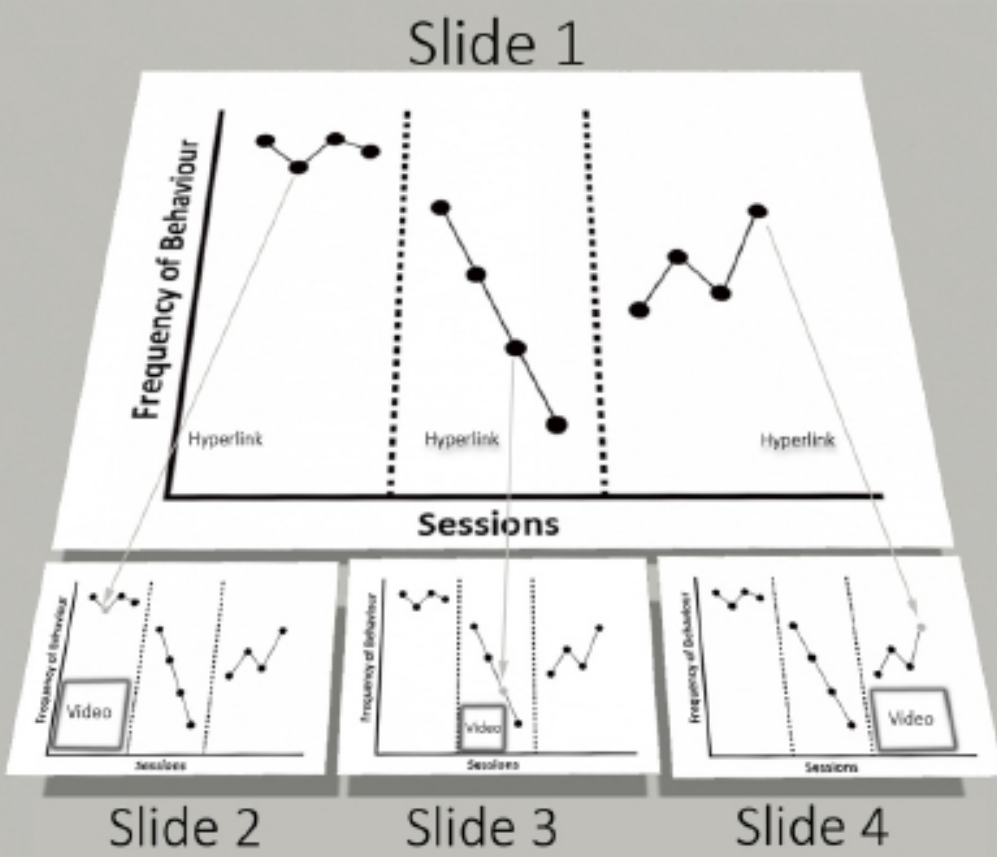

Figure 2. Slide 1 is duplicated and hyperlinks are inserted to the appropriate duplicate containing a video clip.
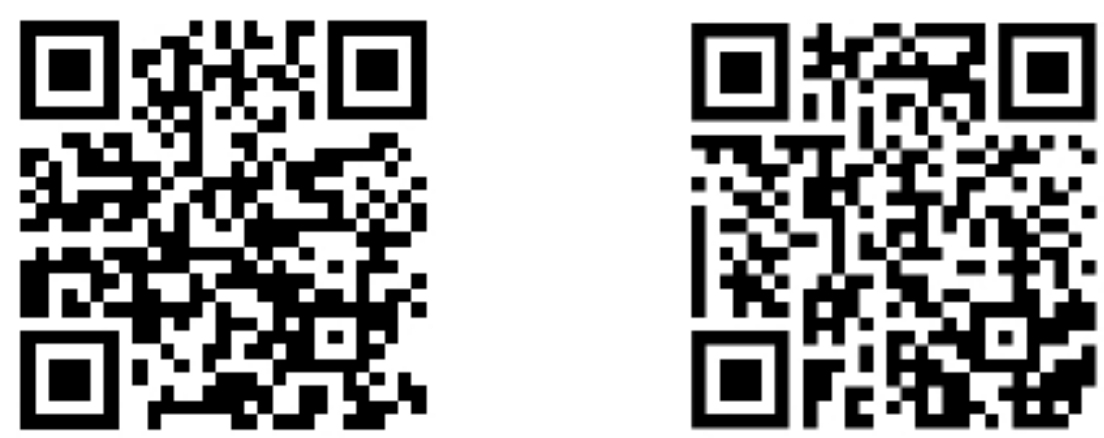

Figure 3. Left: $Q R$ code links to a YouTube presentation on how to use $Q R$ codes. Right: QR code links to a video showing how to teach with Discrete Trials. 

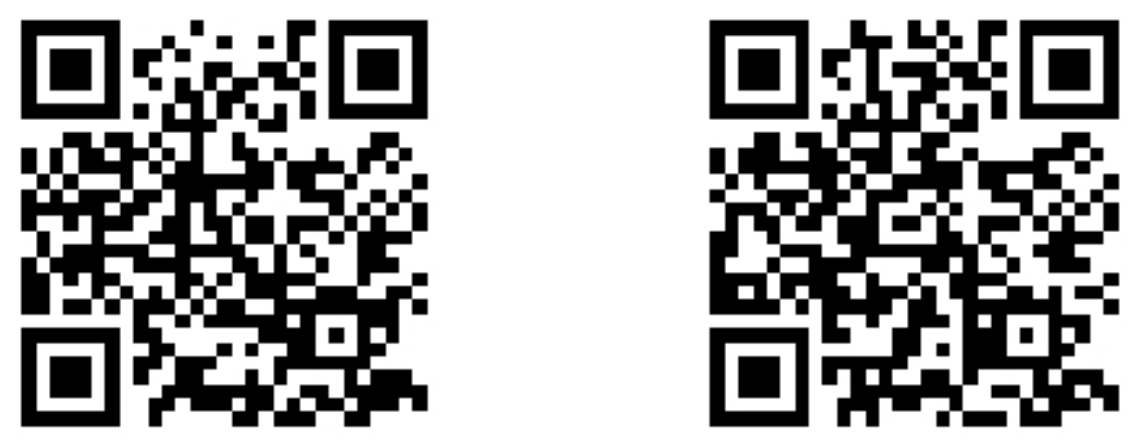

Figure 4. Left: $Q R$ code links to an overview of the Poser software.

Right: QR code links to animation of challenging behaviour.
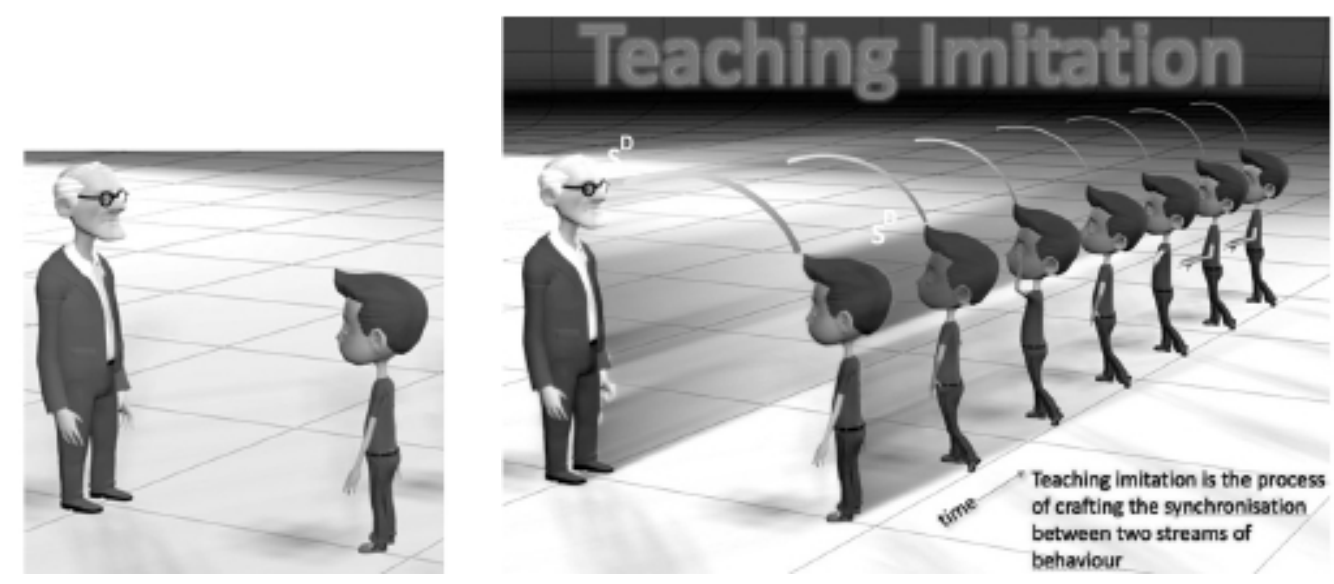

Figure 5. Left: A screenshot from an animation showing imitation.

Right: An illustration showing how the 3D environment can represent changes in time. 


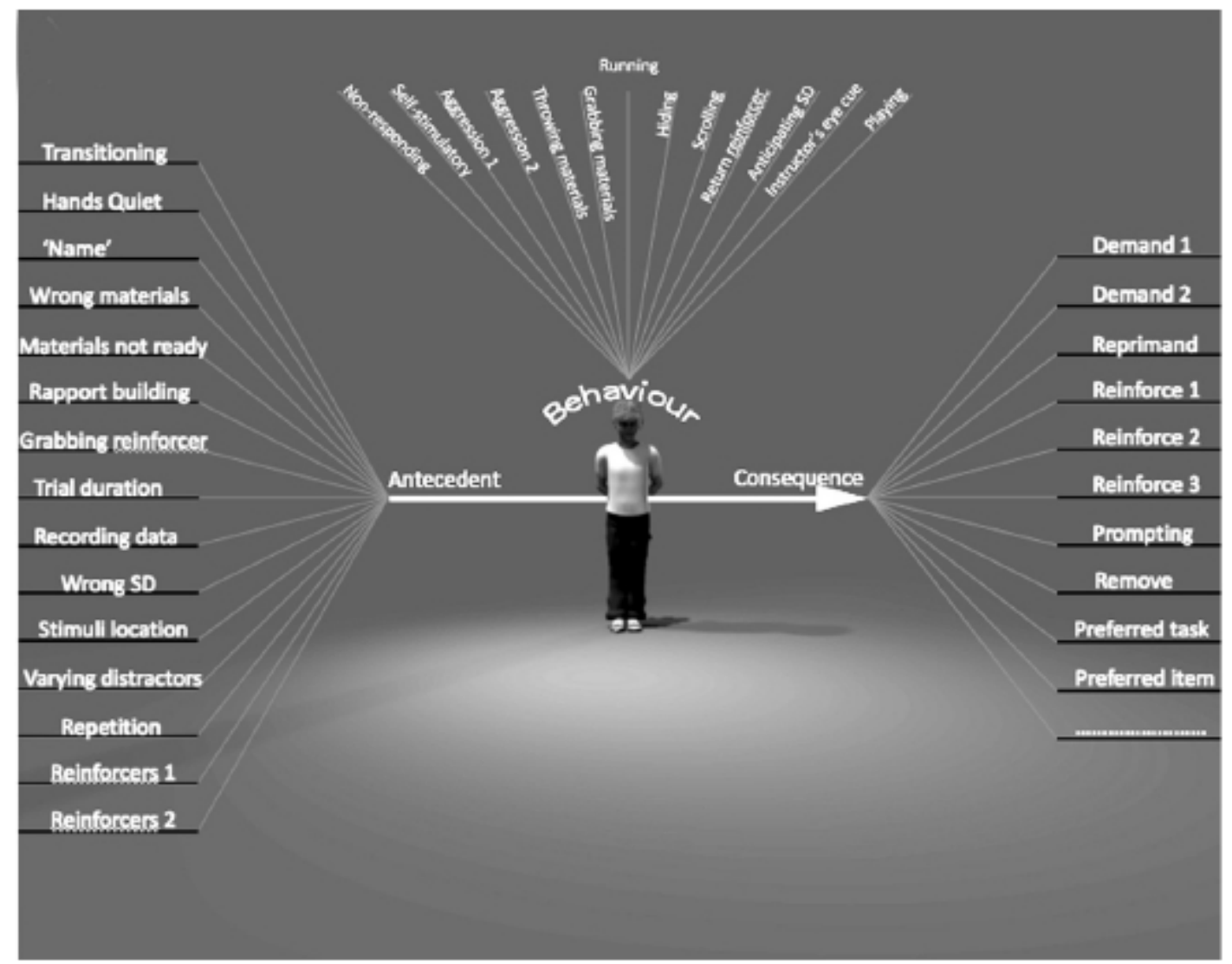

Figure 6. A graphic showing how to arrange compleX information when teaching about Discrete Trials. Each word is a hyperlink that presents an appropriate video clip of the issue to be addressed.

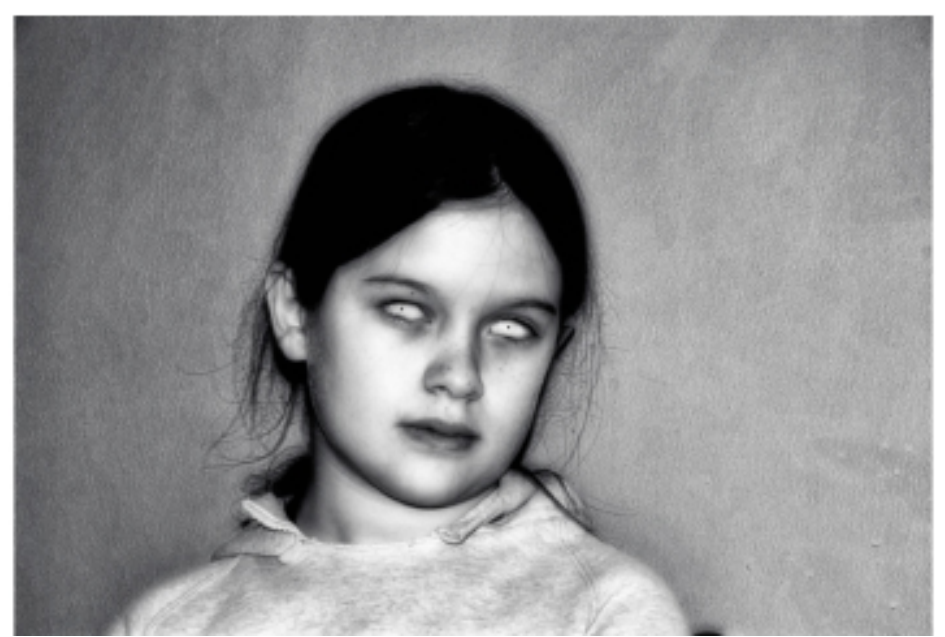

Figure 7. A zombie with no private events? This image shows how a simple change in an image can generate strong reactions in an audience. 


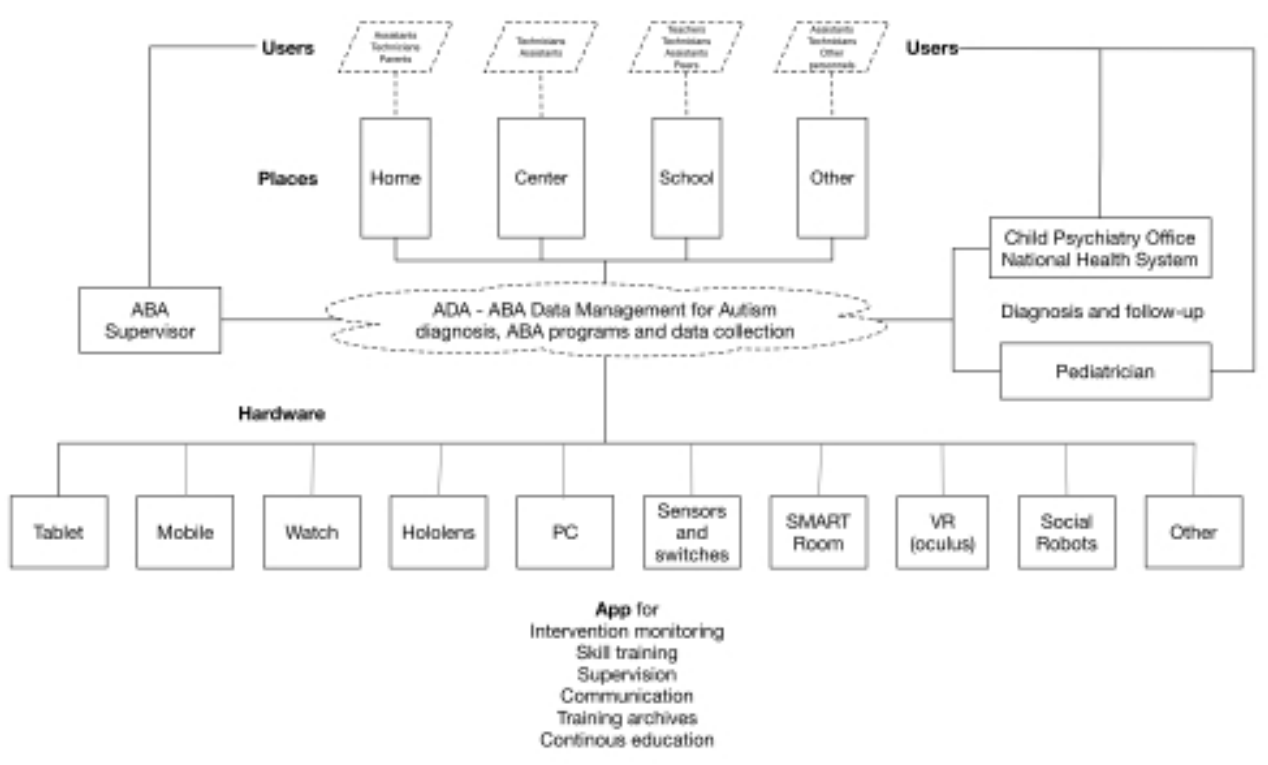

Figure 8. An illustration of the Smart Space for ABA concept.

*A cloud-based repository of data related to progress in ABA-based sessions is linked to a number of platforms across the spaces were interventions take place, ranging from family home, to centres or schools. It connects all the stakeholders of the rehabilitation plan for the child diagnosed with autism. 


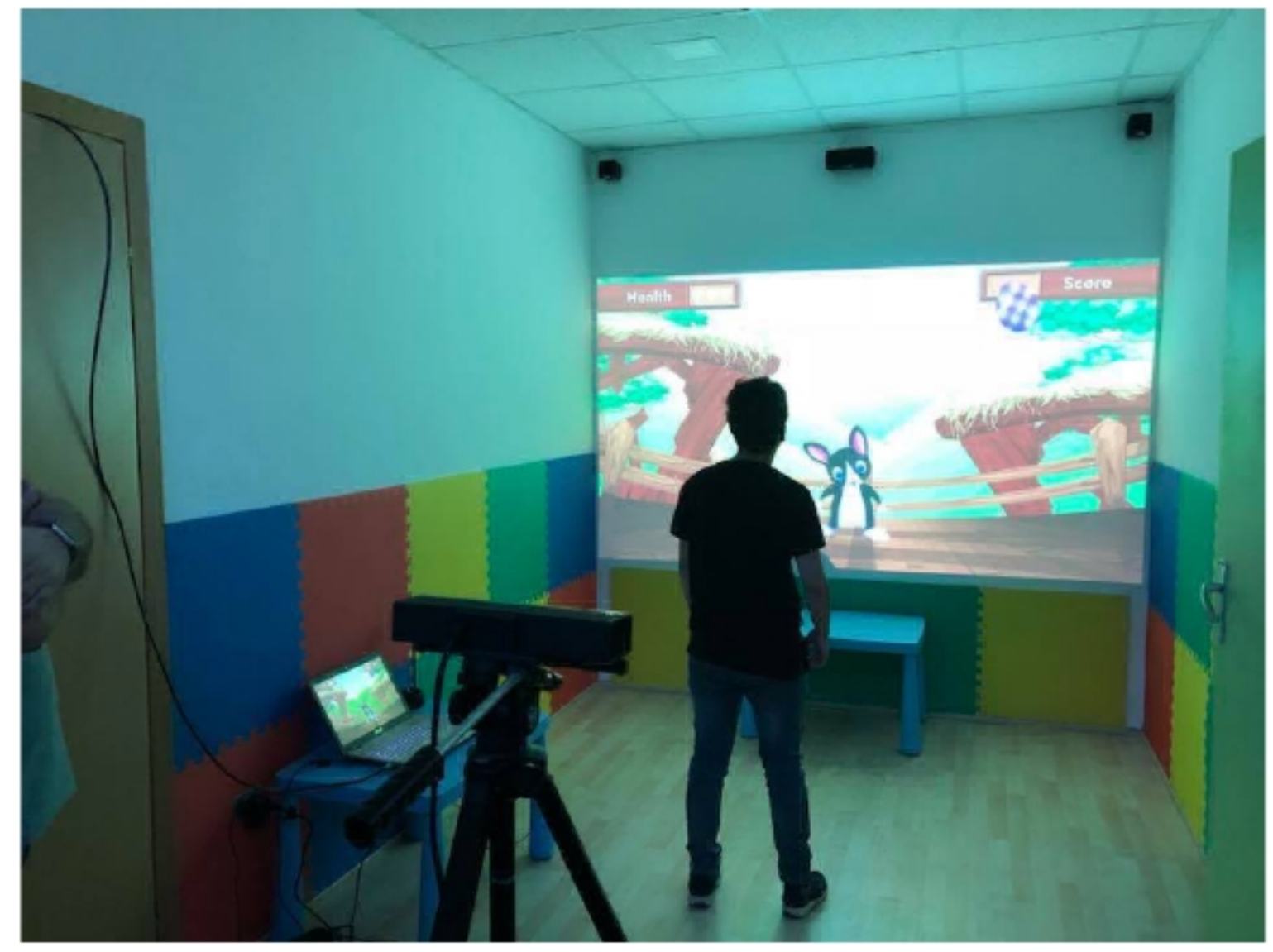

Figure 9. A Smart Room

*A interactive platform based on "Project Mapping" that creates an "Interactive wall" with motor sensors and a projector connected to a computer. A whole therapy room, including furniture and objects, can be transformed into an interactive full-scale touch device, which can offer countless occasions of carefully programmed and tailored learning. 


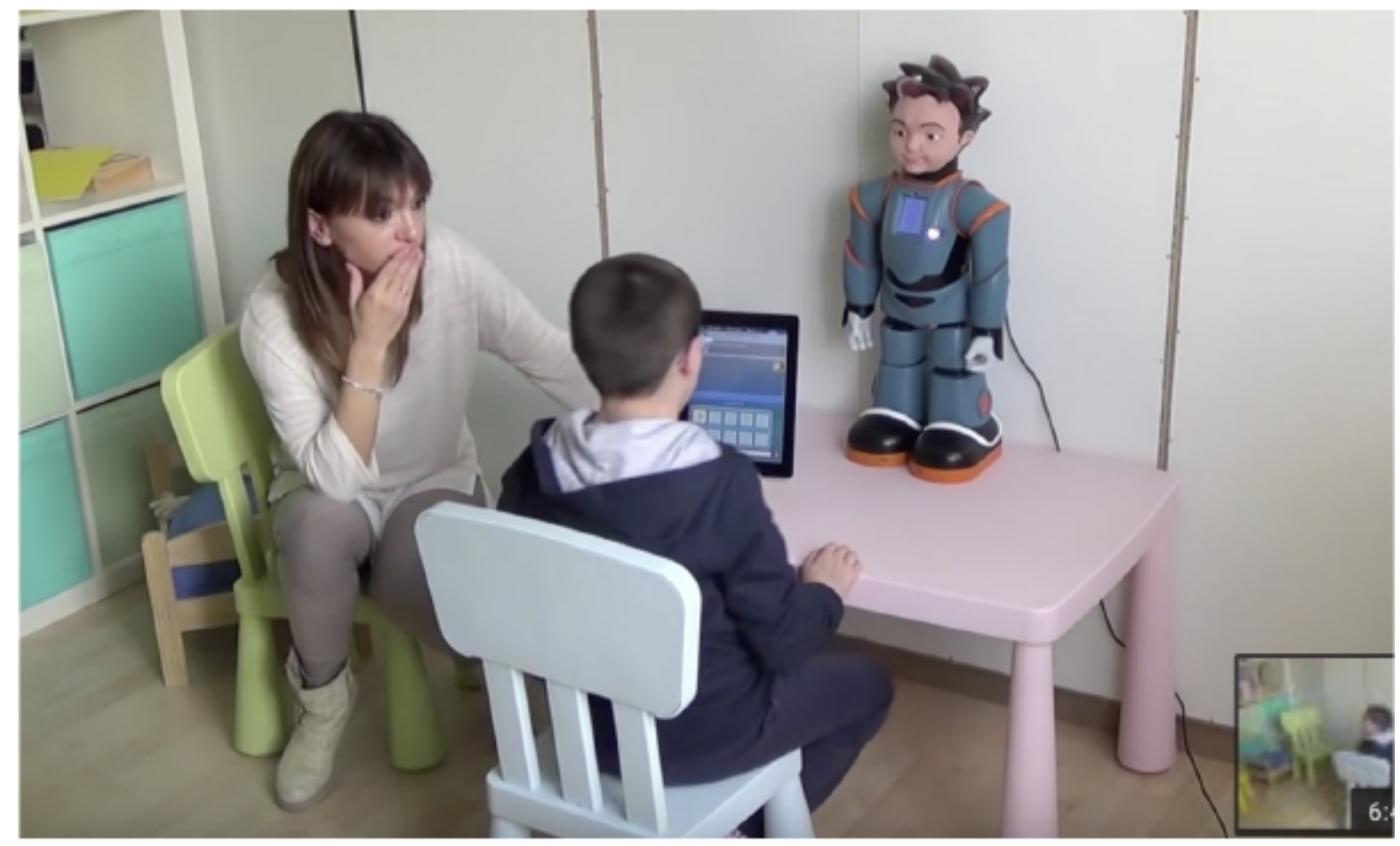

Figure 10. A social robot

*Social robot driven learning interaction in an audio-visual equivalence task. The Robot was programmed to present the audio sample, to prompt the response with a small screen on the chest showing the stimuli that matched the comparisons on the iPad, during an errorless procedure phase, and to offer contingent reinforcers after correct matching. 